had an average of 0.95 (mild disability) versus 0.77 in the RA group, and the average hand function score or Cochin index: 20.6 (moderate disability) against 17.5 of the RA group. There was no statistically significant correlation $\left(\chi^{2}\right)$ between the elevated CRP values and these 2 questionnaires in the SS group. The radiological findings of calcinosis and acroosteólisis in the group with SS were double the cases of the group with RA ( 7 versus 3 , and 14 versus 7 respectively).

Conclusions: Subclinical joint involvement in systemic sclerosis had a high prevalence, similar in rheumatoid arthritis, with ultrasound being a fundamental test when evaluating subclinical inflammatory activity. It also presents an important correlation with the findings found in radiographs in the same locations.

Disclosure of Interest: None declared

DOI: 10.1136/annrheumdis-2018-eular.7102

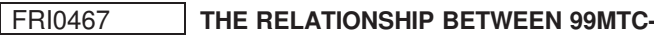 PERTECHNETATE HAND PERFUSION SCINTIGRAPHY AND NAIFOLID CAPILLOSCOPY IN SYSTEMIC SCLEROSIS PATIENTS: A PILOT STUDY}

S.R. Pavlov-Dolijanovic ${ }^{1}$, N. Petrovic ${ }^{2}$, N. Vujasinovic Stupar ${ }^{1}$, N. Damjanov ${ }^{1}$, G. Radunovic ${ }^{1}$, V. Zugic ${ }^{3}$, D. Babic ${ }^{4}$, D. Sobic-Saranovic ${ }^{2}$, V. Artiko ${ }^{2}{ }^{1}$ School of Medicine, University of Belgrade, Institute of Rheumatology, Belgrade, Serbia;

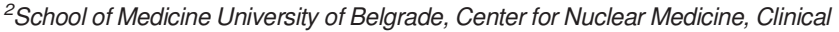
Center of Serbia, Belgrade, Serbia; ${ }^{3}$ School of Medicine, University of Belgrade, Clinic for Pulmology, Clinical Center of Serbia, Belgrade; ${ }^{4}$ School of Medicine University of Belgrade, Institute for Medical Statistics and Informatics, Belgrade, Serbia, Belgrade, Serbia

Background: The aim of this study was to assess possible relationship between the altered blood perfusion at hands analysed by ${ }^{99 \mathrm{~m}} \mathrm{Tc}$-pertechnetate hand perfusion scintigraphy ( $\left.{ }^{99 \mathrm{~m}} \mathrm{TcPHPS}\right)$ and, morphological microvascular abnormalities detected by nailfold capillaroscopy (NC) in SSc patients.

Methods: The study group consisted of 25 patients with SSc (14 with diffuse SSc, and 11 with limited SSc) and 28 control subjects (18 patients with primary $\mathrm{RP}$, and10 healthy individuals). NC and ${ }^{99 \mathrm{~m}} \mathrm{TCPHPS}$ was performed in all the groups examined. The capillaroscopic pattern was classsified as normal or scleroderma ("early", "active", or "late") pattern. Gamma-camera dynamic first-pass study during the first $60 \mathrm{~s}$ and a static scintigraphy after 5 min were recorded following a bolus injection of ${ }^{99 m}$ Tc-pertechnetate via a cubital vein. Regions of interest were drawn on the summed images around the fingers and the palmar region. The fingers-to-palm ratios were then calculated.

Results: SSc patients showed a significantly lower blood flow (BF) and blood pool (BP), $(0.43 \pm 0.21$ vs $0.36 \pm 0.07$, respectively), than PRP patients $(0.45$ \pm 0.18 vs $0.42 \pm 0.06$, respectively) and healthy subjects $(0.58 \pm 0.19$ vs $0.44 \pm 0.06$, respectively), (p-value 0.039 vs 0.004 , respectively). A gradual decrease of $B F$ and BP was found in SSc patients with progressive severity of NVC patterns of microangiopathy ["early" $(0.49 \pm 0.03$ vs $0.39 \pm 0.04$, respectively), "active" $(0.43$ \pm 0.11 vs $0.38 \pm 0.06$, respectively) or "late" $(0.40 \pm 0.28$ vs $0.36 \pm 0.08$, respectively), (p- value 0.462 vs 0.728 respectively], but these differences were not statistically significant. Patients with diffuse SSc showed lower BF, and higher BP $(0.42 \pm 0.26$ vs $0.37 \pm 0.07$, respectively) than those with limited SSc, $(0.44 \pm 0.14$ vs $0.35 \pm 0.064$, respectively), but this differences is not statistical significantly $(p=0.76$ vs $p=0.53$, respectively). There was no significant correlation between BF and BP values and type of SSc (limited or diffuse) ( $r=-0.06, p=0.77 ; r=0.13$, $p=0.54$, respectively) as well as three microangiopathy patterns $(r=-0.253$, $p=0.22 ; r=-0.13, p=0.54$, respectively).

Conclusions: NC represents the best method to analyse microvascular damage in rheumatic diseases, especially SSc. 99m TcPHPS improves the evaluation of vascular damage in SSc patients. There is no direct relationship between these two methods, but one method complements another in the study of vascular damage in SSc patients.

Disclosure of Interest: None declared

DOI: 10.1136/annrheumdis-2018-eular.4268

\section{FRI0468 \\ ABNORMAL OESOPHAGEAL MOTILITY DURING A SOLID TEST MEAL IN SYSTEMIC SCLEROSIS - DETECTION IN VERY EARLY DISEASE AND ASSOCIATION WITH DISEASE PROGRESSION}

S. Bütikofer ${ }^{1}$, S. Jordan ${ }^{2}$, M. Sauter ${ }^{1}$, M. Hollenstein ${ }^{1}$, H. Heinrich ${ }^{1}$, N. FreitasQueiroz $^{3}$,T. Kuntzen ${ }^{1}$, P. Valli ${ }^{1}$, D. Ang ${ }^{4}$, M. Oberacher ${ }^{5}$, B. Maurer ${ }^{2}$,W. Schwitzer ${ }^{1}$, M. Fox ${ }^{1}$, O. Distler ${ }^{2}$, B. Misselwitz ${ }^{1} .{ }^{1}$ Department of Gastroenterology, ${ }^{2}$ Department of Rheumatology, University Hospital Zurich, Zurich, Switzerland; ${ }^{3}$ Department of Gastroenterology, University of Sao Paulo, School of Medicine, Sao Paulo, Brazil; ${ }^{4}$ Department of Gastroenterology, Changi General Hospital, Singapore, Singapore; ${ }^{5}$ Department of Medicine, Spital Limmattal, Schlieren, Switzerland

Background: Ineffective oesophageal motility (IEM) is frequent in patients with systemic sclerosis (SSc). High-resolution oesophageal manometry (HRM) is the reference standard test for oesophageal motility and addition of a test meal increases diagnostic sensitivity and specificity.

Objectives: This study assessed whether using a test meal instead of standard water swallow in HRM increases sensitivity and can detect clinically relevant, abnormal motility in already very early SSc and whether this finding is associated with subsequent disease progression.

Methods: This prospective, longitudinal cohort study recruited 68 consecutive SSc patients (group \#1: 32 established disease (ACR/EULAR 2013 and ACR 1980 criteria fulfilled); group \#2: 24 early disease (only ACR/EULAR 2013 fulfilled); group \#3: 12 very early disease (clinical expert diagnosis of SSc, no classification criteria fulfilled) and 72 healthy controls. HRM evaluated oesophageal motility for water swallows and a solid test meal using validated methods.

Results: SSc patients had less frequent effective oesophageal contractions during the test meal compared to healthy controls. Notably, this was detected even in very early disease $(0.15,1.0,2.1 / \mathrm{min}$ for group \#1, \#2 and \#3, vs. $2.5 / \mathrm{min}$ in health, $p<0.001 ; p<0.001$ and $p<0.009$, respectively). No other significant abnormality on HRM was found in patients with very early disease (group 1). Ineffective motility at HRM was associated with a higher modified Rodnan skin score at baseline. Moreover, at mean $18^{10-31}$ months follow-up, the presence of ineffective motility at baseline was associated with progression of skin disease for the overall SSc cohort $(p<0.010)$. In a secondary analysis, below-average lower oesophageal sphincter pressure was associated with progression of skin disease and organ disease, in particular interstitial lung disease $(p<0.009)$.

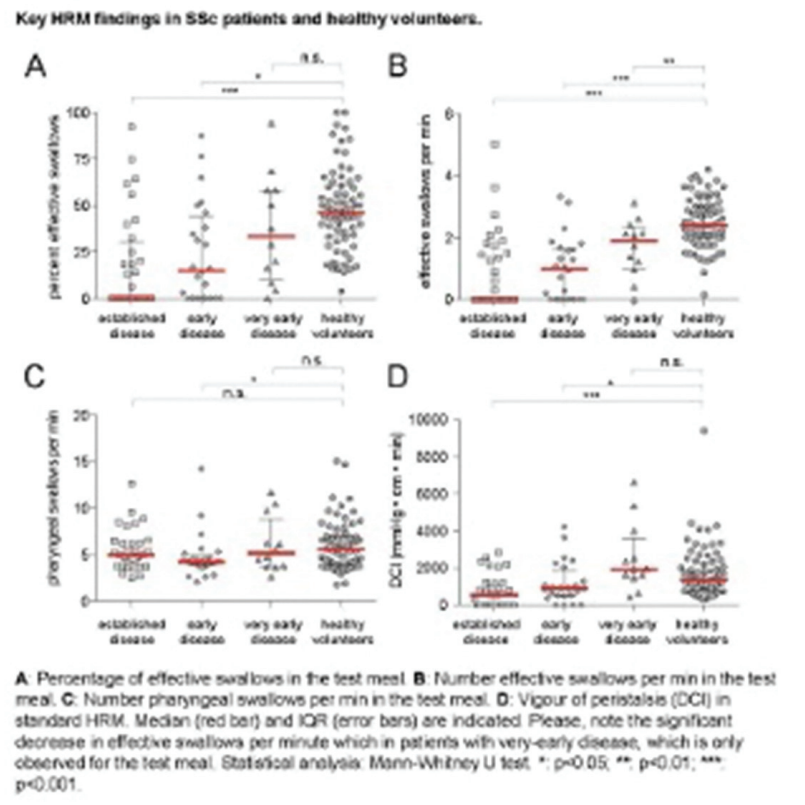

Conclusions: Ineffective motility during a test meal is present already in patients with very early SSc. In cross-sectional analysis, findings on HRM studies at baseline are associated with disease severity and prospectively with progression of 